\title{
Healing of cracks by green laser irradiation in a nanogold particles glass
}

\section{matrix composite}

\author{
Julien Moriceau $^{1, *}$, Patrick Houizot $^{1}$, Maciej Lorenc ${ }^{2}$, Tanguy Rouxel ${ }^{1}$ \\ ${ }^{1}$ Département Mécanique et Verre, Institut de Physique de Rennes, UMR UR1-CNRS 6251, Université de Rennes 1, 35042 Rennes, FRANCE \\ 2 Département Matériaux et Lumière, Institut de Physique de Rennes, UMR UR1-CNRS 6251, Université de Rennes 1,35042 Rennes, FRANCE
}

Keywords: Glass matrix composites; Spark Plasma Sintering; Indentation; Laser treatment; Gold nanoparticles

\begin{abstract}
A transparent composite material consisting of a soda-lime-silicate glass matrix containing up to $0.5 \%_{\mathrm{w}}$ gold nanoparticles $(10$ to $20 \mathrm{~nm}$ ) was successfully obtained by coating glass grains and a subsequent sintering using a spark plasma sintering (SPS) furnace. Coating was achieved thanks to the reduction of gold(III) chloride trihydrate by sodium borohydride in an ethanol solution. The sintered composites were dense and transparent, but for the largest gold content where the sample exhibits a deep red color. When submitted to laser irradiation $\left(532 \mathrm{~nm}\right.$, up to $\left.100 \mathrm{~W} / \mathrm{cm}^{2}\right)$, the composite experiences a fast, localized and much more significant increase of its temperature in comparison with the pristine glass material. A temperature as high as $550{ }^{\circ} \mathrm{C}$ was reached, allowing the healing of surface crack.
\end{abstract}

\section{Introduction}

Crack exhibiting healing phenomena were scarcely reported in the literature [1]. In healing polymers the common approaches use the vascular network [2,3] or reactive particles [4] which fill the cracks that propagate across them. Another method is to favor some relaxation process by triggering atoms mobility with an external source of energy [5]. In oxide glasses the atoms mobility is much lower than in polymers and high temperatures are required to observe some relaxation phenomenon within a "reasonable" time (say less than an hour). Besides oxide glasses are mostly elaborated at high temperature, typically above $1200{ }^{\circ} \mathrm{C}$, and the second phase particles that are introduced with the aim to promote healing must be

\footnotetext{
*Corresponding author: julien.moriceau @univ-rennes1.fr
} 
chosen with much care to survive the synthesis cycle. For example, Coillot et al. [6] dispersed vanadium boride particles in a barium aluminosilicate glass by SPS and they observed the healing of indentation cracks after the particles melted and reacted with the matrix due to the combination of an oxidizing environment and a high temperature. Singh [7] promoted healing at indentation cracking sites by heat treating a window glass in the transition range, hence inducing viscous relaxation. However, the drawback of these two latter methods is the global heating of the material up to high temperatures which might be detrimental to the conservation of the geometry of the component and may thus not be suitable to industrial application. Besides, the dispersion of particles mostly results in the loss of transparency [1, 6]. In this article we suggest a new approach based on the incorporation of gold nanoparticles in a transparent glass and a localized laser heating in damaged areas.

Nanogold glass composites were already produced by glass craftsmen centuries ago in order to brighten red glasses. Historically the coloration of the glass was obtained by direct addition of gold in the glass melt and further heat treatments [8]. Nowadays similar glasses can be obtained by various methods such as sol-gel [9-11] or high energy irradiation of Au containing glass [8, 12, 13]. Such composites are of interest for biomedical $[9,10,14]$ and optical [12] applications and for historical purposes as well [8, 13]. Indeed gold nanoparticles (GNP) can enhance the bone regeneration via the surface plasmon resonance (SPR) or significantly affect the optical properties (color, refractive index). The gold SPR occurring at 532 $\mathrm{nm}$ is also used to induce heating by laser irradiation $[15,16]$. This technique allows for a localized heating by promoting a strong laser/material interaction [16-18].

In the present work, nanoparticles of gold were coated at the surface of window glass particles and the coated particles were then sintered by spark plasma sintering (SPS). Vickers indentation was performed at the surface of the obtained material and the indentation site was further submitted to laser irradiation to promote crack healing. 


\section{Materials and methods}

Window glass spherical particles were purchased from HD-Outillage with a diameter in the 40 to $70 \mu \mathrm{m}$ range. The coating of $\mathrm{Au}$ on glass particles was achieved by reduction of gold(III) chloride trihydrate $\left(\mathrm{HAuCl}_{4} \cdot 3 \mathrm{H}_{2} \mathrm{O}\right.$, Sigma-Aldrich, >99.9\%) by sodium borohydride $\left(\mathrm{NaBH}_{4}\right.$, Sigma-Aldrich, $\left.>98 \%\right)$ in ethanol following the protocol reported by Kaneti et al. [19]. Different amounts $(0.01,0.02,0.05,0.1,0.2$ and $0.5 \%_{\mathrm{w}}$ ) of gold were deposited by tuning the amount of reactants. The gold content was calculated by assuming that the reaction of ionic gold with sodium borohydride was complete and that the obtained gold is entirely deposited on the glass particles. The relative error on the gold content is then estimated at around $5 \%$. A broad range of colored glasses were obtained (see Figure 1). After the drying of the powder some purple aggregates of gold were observed for samples containing more than $0.1 \%$ of gold. These aggregates were removed from the powder mixture. A presintering step of $1 \mathrm{~g}$ of coated glass particles was performed in a silica mold (diameter $10 \mathrm{~mm}$ ) at $700{ }^{\circ} \mathrm{C}$ during $20 \mathrm{~min}$ to limit the carbon contamination that may further occur during the subsequent SPS step [20]. After presintering, a pellet of $10 \mathrm{~mm}$ was obtained and introduced in a graphite die protected by a $220 \mu \mathrm{m}$ thickness carbon paper (Papyex, Mersen). SPS sintering step was done using a KCE-FCT-HP D 10-SD system with a temperature plateau at $625{ }^{\circ} \mathrm{C}$ during $1.5 \mathrm{~min}$ under a pressure of $64 \mathrm{MPa}$. The heating rate was set at $100{ }^{\circ} \mathrm{C} / \mathrm{min}$. After the heating stage, the sample was cooled down to room temperature by switching the power off. $30 \mathrm{~g}$ of the uncoated glass particles were also melted for $2 \mathrm{~h}$ at $1500{ }^{\circ} \mathrm{C}$ to be used as a reference. After quenching the liquid in a brass mould an annealing heat treatment was done for $2 \mathrm{~h}$ at $570{ }^{\circ} \mathrm{C}$ and followed by a slow cooling down to room temperature. 


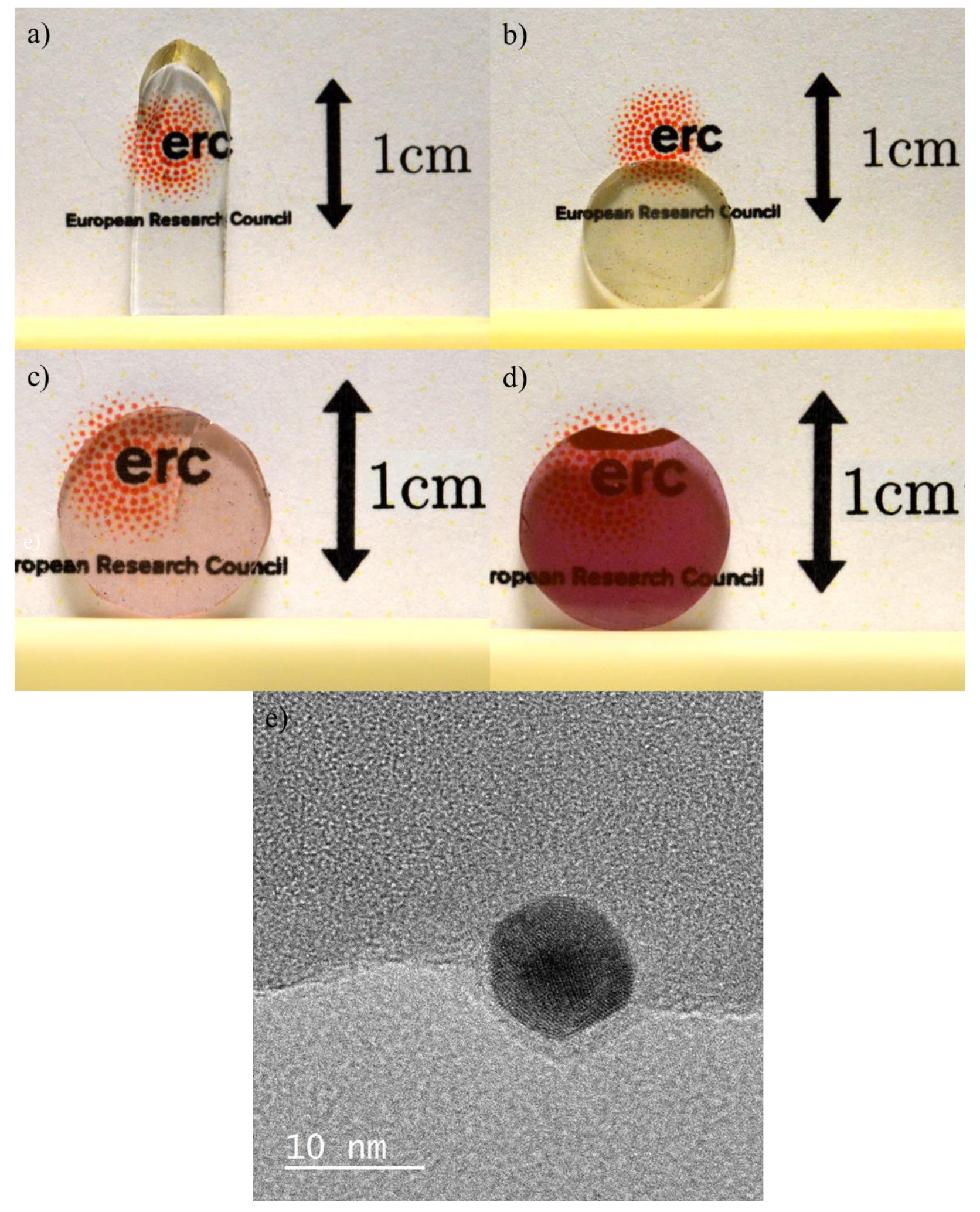

Figure 1: a) Pristine quenched glass; b) Sintered glass; c) Sample containing $0.01 \%_{w}$ of gold; d) Sample containing $0.2 \%$ of gold; e) TEM image of a GNP coated on the glass. 
The density of the sintered samples was measured from 5 measurements by the Archimedes method in water. The mean error on the relative density was around $0.1 \%$. The transmittance of the composites (thickness $1.7 \mathrm{~mm}$ ) was recorded by a PerkinElmer Lambda 900 spectrophotometer between 200 and $800 \mathrm{~nm}$ with a precision slot of $2 \mathrm{~nm}$. Vickers indents were performed with a Matsuzawa VMT-7S apparatus with a load of $10 \mathrm{~N}$ applied for $15 \mathrm{sec}$. The laser irradiation was implemented by an unfocused (spot size: $2.25 \mathrm{~mm} \pm 10 \%$ ) continuous irradiation of a Coherent Verdi series V G5 laser emitting at $532 \mathrm{~nm}$. The temperature measurement was done by a FLIR camera positioned $15 \mathrm{~cm}$ and $30^{\circ}$ on the right of the sample and focused on the surface. The relative error on the temperature measurement is around $10 \%$. Observation of crushed glass grains coated with $0.5 \%$ of GNPs was performed by means of a JEOL 2100 TEM under a voltage of $200 \mathrm{keV}$. The glass transition and softening temperatures of the initial glass were measured with a L75 PT Linseis vertical dilatometer at a rate of $10{ }^{\circ} \mathrm{C} / \mathrm{min}$ with a precision of $\pm 5^{\circ} \mathrm{C}$.

\section{Results and Discussion}

The sintering of the pristine glass grains leads to fairly transparent samples (see Figure 1). When Au is coated on the glass particles, the sample after sintering are colored from pink to purple with a slight decrease of the transparency as the amount of gold is increased even though the relative density is maintained above $99.5 \%$ in all cases. The optical transmittance spectra in the visible range are shown in Figure 2a. The average transmission of the gold free sintered glass is slightly inferior to the one of the samples containing 0.01 and $0.02 \%$ of gold. This can be due to trapped bubbles created by uneven beads packing before the presintering step. As the gold amount is increased, the transparency decreases because of the formation of gold agglomerates, which are clearly visible in the glasses containing between 0.1 and $0.5 \%_{\mathrm{w}}$ of gold. An absorption peak is visible at around $532 \mathrm{~nm}$ in all spectra of gold containing samples. It is due to the SPR of GNP. The SPR is very dependent of the size and geometry of the nanocrystal [2123] and was reported from $511 \mathrm{~nm}$ [8] to $556 \mathrm{~nm}$ [13]. The observation of the GNP with the TEM shown the particles diameter was comprised in between 10 and $20 \mathrm{~nm}$ (Figure 1). Although the particles were too small to observe any diffraction pattern, the lattice parameter of the observed NPs was found to be 
consistent with the (111) plans of metallic gold (ICSD: 00-004-0784). In order to better compare the absorption of the different samples, spectra were normalized by the maximum transmission (usually around $800 \mathrm{~nm}$ ) and the results are plotted in Figure 2b. 

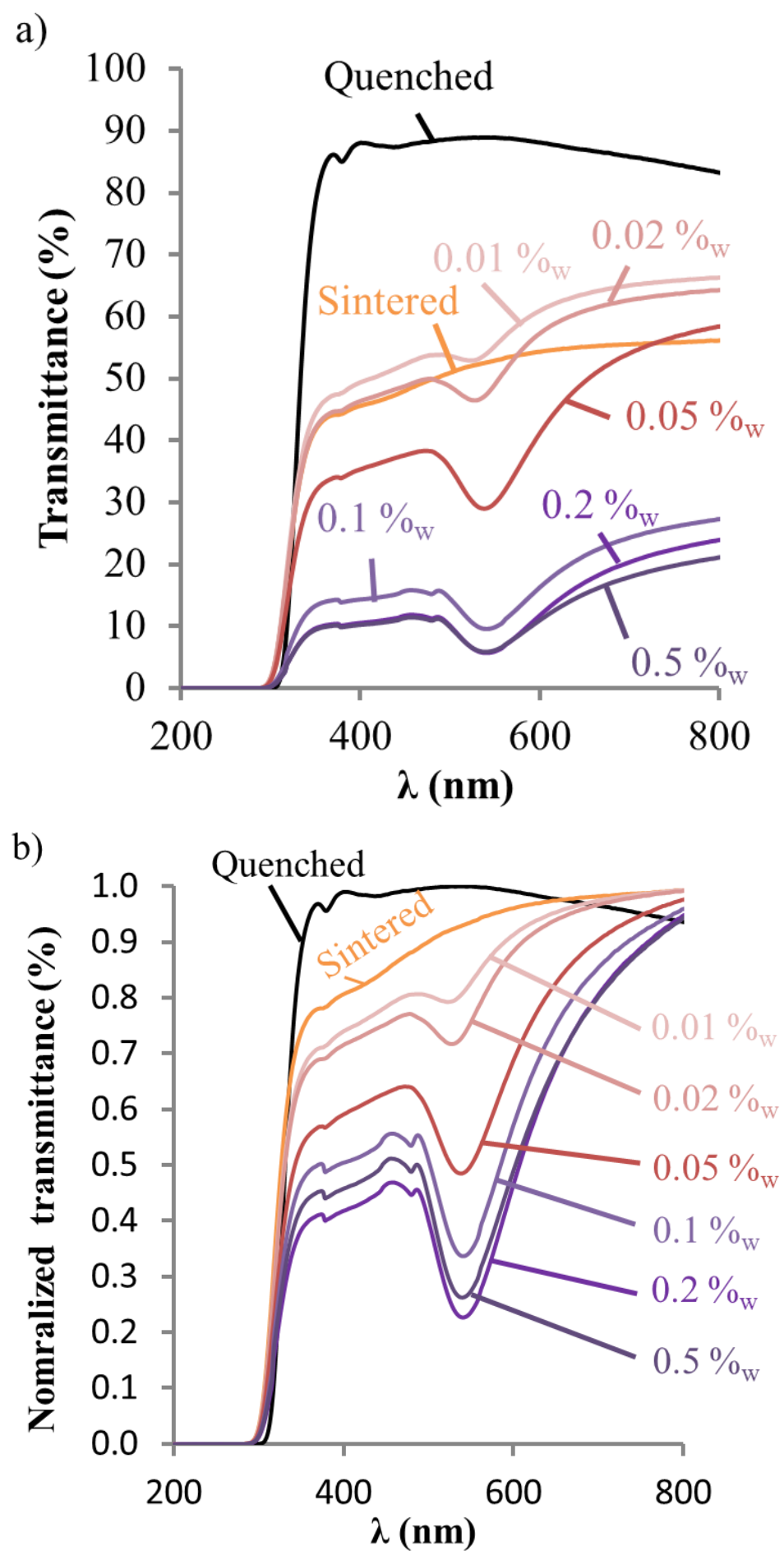

Figure 2: a) Transmittance in the visible range of the different composites and glass between 200 and $800 \mathrm{~nm}$; b) Normalized transmittance in the visible range of the different composites and glass between 200 and $800 \mathrm{~nm}$. 
An increase of the wavelength of the SRP with the GNP amount is noticed, from 522 to $540 \mathrm{~nm}$ as the GNP fraction is increased from 0.01 to $0.1 \%$. This implies an increase in the average size of the nanoparticles with an increase of gold weight percent [24]. Figure $2 \mathrm{~b}$ shows that the absorption peak is more and more intense as the gold amount is increased. However the sample with $0.2 \%_{\mathrm{w}}$ absorbs nearly as much light as the sample with $0.5 \%_{\mathrm{w}}$ which is likely due to the fact, that above $0.2 \%_{\mathrm{w}}$, gold cannot coat more surface and thus form larger aggregates in the solution.

Iron impurity is common in window glass and is characterized by two absorption peaks at 380 and $450 \mathrm{~nm}$ due to $\mathrm{Fe}^{3+}$. Moreover $\mathrm{Fe}^{2+}$ creates a large shoulder for wavelength above $450 \mathrm{~nm}$ and is responsible for the decrease of the transmittance in this large wavelength range in the quenched glass sample [25]. This latter trend is not observed in the sintered sample as the transmittance continuously decreases with the decrease of the wavelength, likely because of carbon contamination from the SPS treatment as a $40 \mathrm{~nm}$ layer of carbon can impact the transmittance over the entire visible spectrum [26]. 

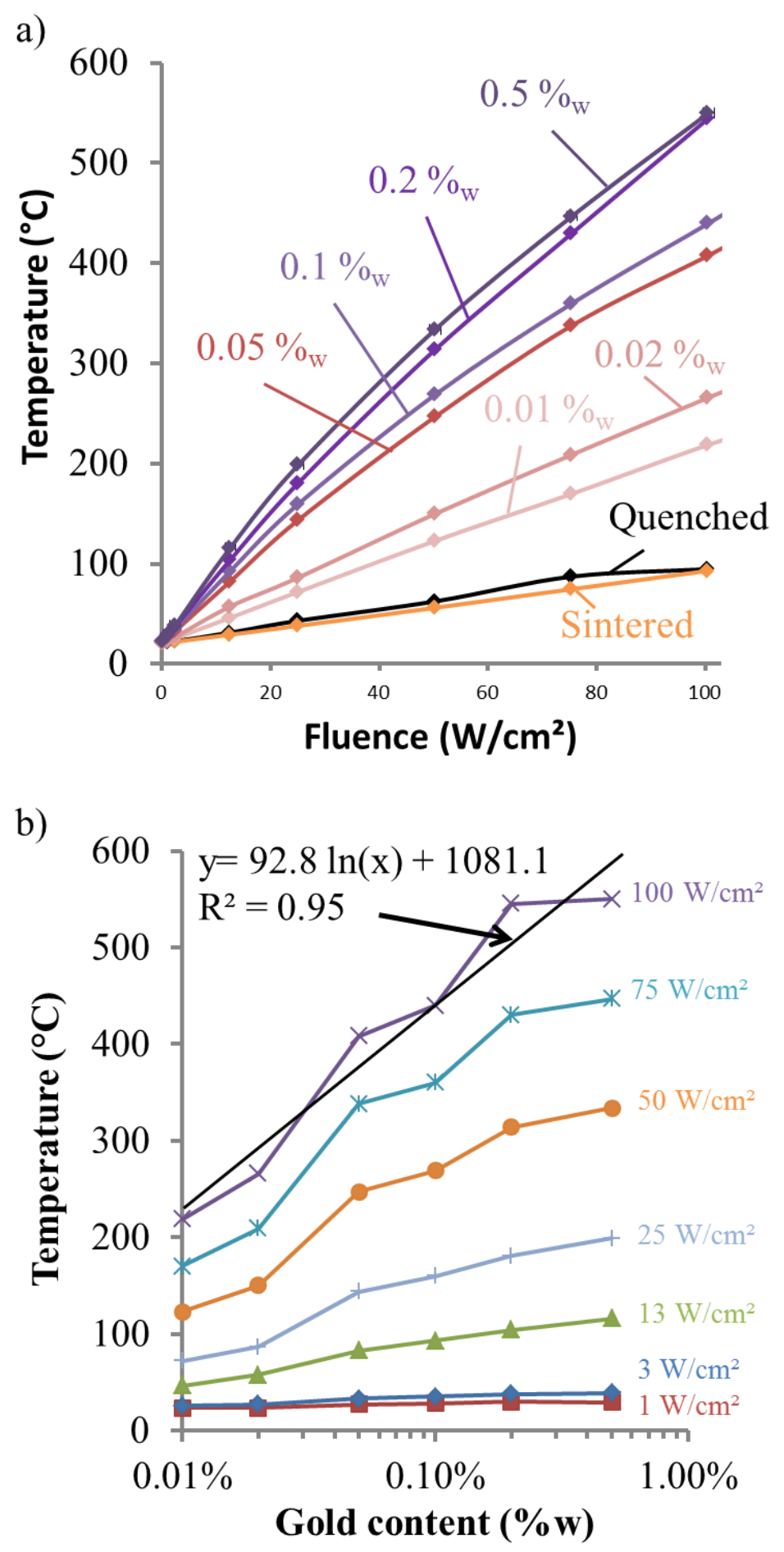

Figure 3: a) Evolution of the temperature with the laser power for different gold content (in weight percent); b) Increase of the temperature as a function of the gold content for different laser powers. 
The irradiation of the sample was done by progressively increasing the laser beam power step by step up to $100 \mathrm{~W} / \mathrm{cm}^{2}$ with a $3 \mathrm{~min}$ long plateau at each step $\left(1.3,2.5,12.5,25,50,75\right.$ and $\left.100 \mathrm{~W} / \mathrm{cm}^{2}\right)$. The temperature at the end of each step was recorded (Figure 3a). The temperature of the quenched glass reached $110{ }^{\circ} \mathrm{C}$ at the end of the irradiation cycle, thanks to a partial absorption at $532 \mathrm{~nm}$ due to the presence of $\mathrm{Fe}^{2+}$. The pristine sintered glass showed a lower temperature increase compared to the quenched one due to the diffusion of light in the sample resulting from the residual porosity. Samples containing GNP were submitted to the same cycle but showed a larger temperature increase under irradiation due to the laser/GNP interaction, which is effective even for gold content as small as $0.01 \%_{\mathrm{w}}$, as evidenced by the temperature of $200{ }^{\circ} \mathrm{C}$ reached in the latter case at maximum illumination. The increase of the achieved temperature is nearly linear with the laser power (Figure 3a) and evolves logarithmically with the gold content $\left(\mathrm{R}^{2}>0.95\right.$, Figure $\left.3 \mathrm{~b}\right)$. The maximum temperature is $550{ }^{\circ} \mathrm{C}$ and is reached with the $0.5 \%$ w gold content composite.

The glass transition and softening temperatures of the original glass are at 570 and $616{ }^{\circ} \mathrm{C}$ respectively, as determined by dilatometry. The gold content being smaller than $0.5 \%$, the influence of gold on these characteristic temperatures is supposed to be negligible. As the maximum temperature reached by the composite with the largest gold content is close to the glass transition temperature, some healing due to viscous relaxation is expected. To investigate this possibility, a Vickers indent of $10 \mathrm{~N}$ was made on the surface of the sample containing $0.5 \% \mathrm{w}$ of GNP. The indented area was then submitted to laser irradiation for 10 min with a fluence set at $100 \mathrm{~W} / \mathrm{cm}^{2}$. A temperature of $550{ }^{\circ} \mathrm{C}$ was recorded at the indentation site during the whole experiment, which was found to induce an efficient healing of the indentation cracks (Figure 4). The indent cracks are found to shorten and to significantly open, with a concomitant blunting of the tip, after the healing treatment. Besides the indentation imprint is found to shrink as the glass temperature gets close to the transition temperature $\left(570{ }^{\circ} \mathrm{C}\right.$ as measured with a dilatometer at $\left.10{ }^{\circ} \mathrm{C} / \mathrm{min}\right)$. 


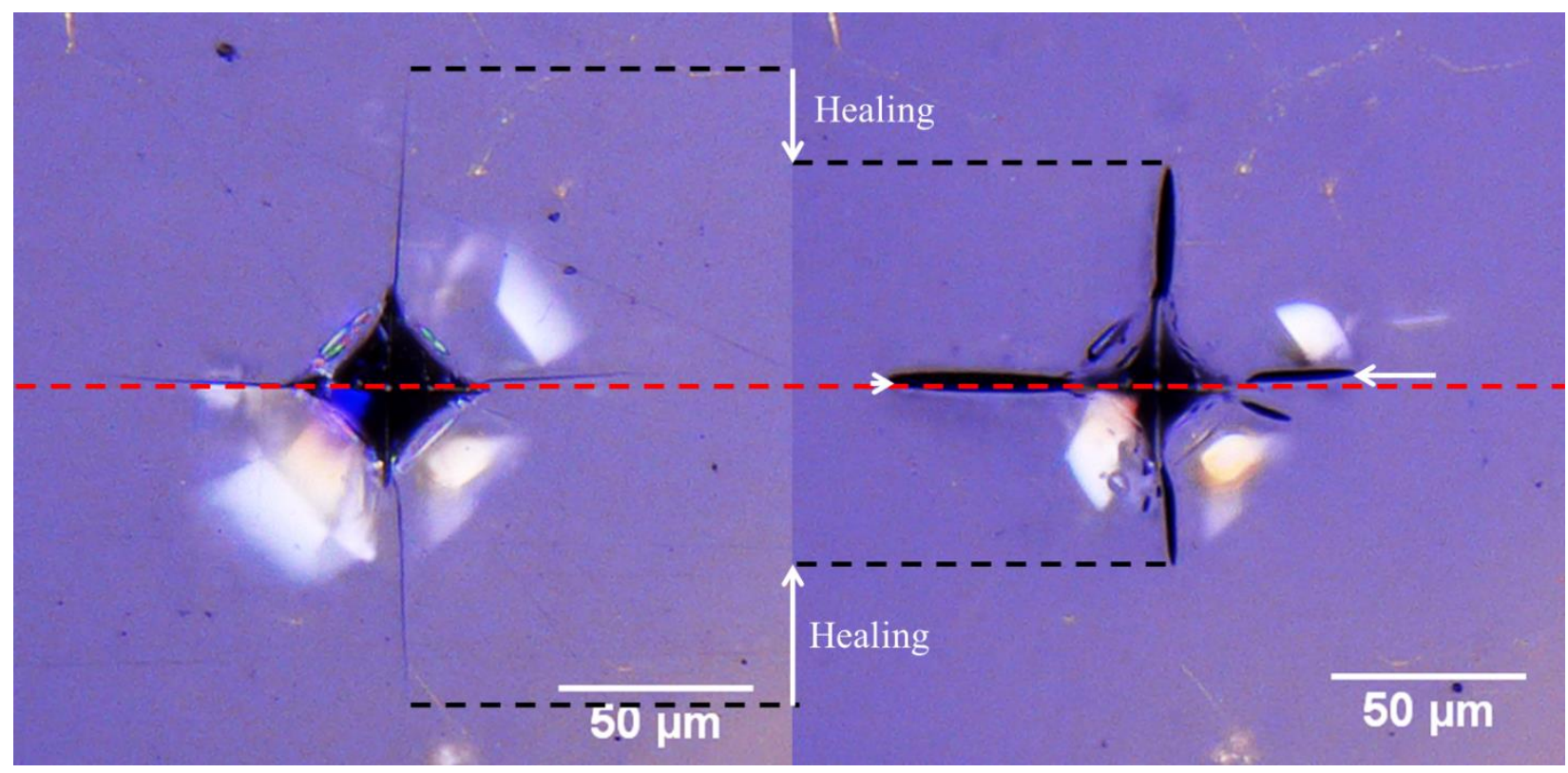

Figure 4: Indent before (left) and after $10 \mathrm{~min}$ at $550^{\circ} \mathrm{C}$ (right). The red and black dashed lines represent guides for the eyes. The white arrows represent the decrease in crack length and by consequence the healing. 


\section{Conclusions}

We have presented a method to coat gold on window glass particles by reduction of ionic gold by sodium borohydride. This method is versatile and can be applied to different glass composition. The SPS sintering of the glass grains leads to dense translucent samples. The coating of gold nanoparticles was tailored by changing the reactant content in the solution in order to synthesized materials with up to $0.5 \%_{\mathrm{w}}$ gold resulting in a progressive shift of the color from light pink to bright purple. The laser illumination of gold containing samples enabled the heating of the glass due to the SRP of the GNP. This was shown to result in a partial healing of the indentation crack and imprint of an indent after only $10 \mathrm{~min}$ of treatment.

These preliminary investigations are encouraging and open new perspectives for the curing of mechanical damage at the surface of glass and possibly in the volume as well. In the future, other noble metal and less refractory glasses (lower $\mathrm{T}_{\mathrm{g}}$ ) will be investigated with the aim to decrease the cost.

\section{Acknowledgments}

The European Research Council is greatly acknowledged for the Advanced Grant 320506 (DAMREG) of the $7^{\text {th }}$ framework program "Ideas". We would like to thank J. Troles and L. Calvez (Institut National des Sciences Chimiques de Rennes) and E. Gallou (Institut de Physique de Rennes) for their technical support and providing us with IR Camera and SPS equipment. We further thanks V. Dorcet (THEMIS platform, Université de Rennes 1) for TEM observations.

\section{References}

[1] V. Amendola, M. Meneghetti, Advances in self-healing optical materials, Journal of Materials Chemistry, 22 (2012) 24501-24508.

[2] M.W. Lee, S. An, S.S. Yoon, A.L. Yarin, Advances in self-healing materials based on vascular networks with mechanical self-repair characteristics, Advances in Colloid and Interface Science, 252 (2018) 21-37.

[3] S.R. White, N.R. Sottos, P.H. Geubelle, J.S. Moore, M.R. Kessler, S.R. Sriram, E.N. Brown, S. Viswanathan, Autonomic healing of polymer composites, Nature, 409 (2001) 794-797.

[4] A.C. Jackson, J.A. Bartelt, P.V. Braun, Transparent self-healing polymers based on encapsulated plasticizers in a thermoplastic matrix, Advanced Functional Materials, 21 (2011) 4705-4711. 
[5] P. Froimowicz, H. Frey, K. Landfester, Towards the generation of self-healing materials by means of a reversible photo-induced approach, Macromolecular Rapid Communications, 32 (2011) 468-473.

[6] D. Coillot, F.O. Méar, R. Podor, L. Montagne, Influence of the active particles on the self-healing efficiency in glassy matrix, Advanced Engineering Materials, 13 (2011) 426-435.

[7] R.N. Singh, Kinetics of self-repair in inorganic glasses: modeling and experimental verification, J Mater Sci, 49 (2014) 4869-4879.

[8] A. Ruivo, C. Gomes, A. Lima, M.L. Botelho, R. Melo, A. Belchior, A. Pires de Matos, Gold nanoparticles in ancient and contemporary ruby glass, Journal of Cultural Heritage, 9 (2008) e134-e137.

[9] K. Magyari, T. Nagy-Simon, A. Vulpoi, R.A. Popescu, E. Licarete, R. Stefan, K. Hernádi, I. Papuc, L. Baia, Novel bioactive glass-AuNP composites for biomedical applications, Materials Science and Engineering: C, 76 (2017) 752-759.

[10] S. Simon, R. Ciceo-Lucacel, T. Radu, L. Baia, O. Ponta, A. Iepure, V. Simon, Gold nanoparticles developed in sol-gel derived apatite-bioactive glass composites, Journal of Materials Science: Materials in Medicine, 23 (2012) 1193-1201.

[11] G. Lusvardi, G. Malavasi, V. Aina, L. Bertinetti, G. Cerrato, G. Magnacca, C. Morterra, L. Menabue, Bioactive glasses containing Au nanoparticles. Effect of calcination temperature on structure, morphology and surface properties, Langmuir, 26 (2010) 10303-10314.

[12] N. Nedyalkov, N.E. Stankova, M.E. Koleva, R. Nikov, M. Grozeva, E. Iordanova, G. Yankov, L. Aleksandrov, R. Iordanova, D. Karashanova, Optical properties modification of gold doped glass induced by nanosecond laser radiation and annealing, Optical Materials, 75 (2018) 646-653.

[13] M. Eichelbaum, K. Rademann, R. Müller, M. Radtke, H. Riesemeier, W. Görner, On the chemistry of gold in silicate glasses: studies on a nonthermally activated growth of gold nanoparticles, Angewandte Chemie International Edition, 44 (2005) 7905-7909.

[14] V. Aina, G. Cerrato, G. Martra, L. Bergandi, C. Costamagna, D. Ghigo, G. Malavasi, G. Lusvardi, L. Menabue, Gold-containing bioactive glasses: a solid-state synthesis to produce alternative biomaterials for bone implantations, Journal of The Royal Society Interface, 10 (2013) 20121040.

[15] P. Keblinski, D.G. Cahill, A. Bodapati, C.R. Sullivan, T.A. Taton, Limits of localized heating by electromagnetically excited nanoparticles, Journal of Applied Physics, 100 (2006) 054305.

[16] D.K. Roper, W. Ahn, M. Hoepfner, Microscale Heat Transfer Transduced by Surface Plasmon Resonant Gold Nanoparticles, The journal of physical chemistry. C, Nanomaterials and interfaces, 111 (2007) 3636-3641.

[17] N.N. Nedyalkov, A.P. Atanasov, R. Toshkova, E. Gardeva, L. Yossifova, M. Alexandrov, D. Karashanova, Laser heating of gold nanoparticles: photothermal cancer cell therapy, in: SPIE Photonics Europe, SPIE, 2012, pp. 7.

[18] E. Sassaroli, K.C.P. Li, B.E. O'Neill, Numerical investigation of heating of a gold nanoparticle and the surrounding microenvironment by nanosecond laser pulses for nanomedicine applications, Physics in Medicine \& Biology, 54 (2009) 5541.

[19] Y. Kaneti, J. Moriceau, M. Liu, Y. Yuan, M. Quadir, X. Jiang, A. Yu, Hydrothermal synthesis of ternary $\alpha-\mathrm{Fe}_{2} \mathrm{O}_{3}-\mathrm{ZnO}-\mathrm{Au}$ nanocomposites with high gas-sensing performance, Sensors and Actuators B: Chemical, 209 (2015) 889-897.

[20] A. Bertrand, J. Carreaud, G. Delaizir, J.-R. Duclère, M. Colas, J. Cornette, M. Vandenhende, V. Couderc, P. Thomas, A comprehensive study of the carbon contamination in tellurite glasses and glassceramics sintered by spark plasma sintering (SPS), Journal of the American Ceramic Society, 97 (2014) 163-172.

[21] S. Link, M.A. El-Sayed, Size and temperature dependence of the plasmon absorption of colloidal gold nanoparticles, The Journal of Physical Chemistry B, 103 (1999) 4212-4217.

[22] A. Vincenzo, P. Roberto, F. Marco, M.M. Onofrio, I. Maria Antonia, Surface plasmon resonance in gold nanoparticles: a review, Journal of Physics: Condensed Matter, 29 (2017) 203002.

[23] R. Rodríguez-Oliveros, J.A. Sánchez-Gil, Gold nanostars as thermoplasmonic nanoparticles for optical heating, Opt. Express, 20 (2012) 621-626. 
[24] Y.J. Zhang, Investigation of gold and silver nanoparticles on absorption heating and scattering imaging, Plasmonics, 6 (2011) 393-397.

[25] W. Meulebroeck, K. Baert, A. Ceglia, P. Cosyns, H. Wouters, K. Nys, H. Terryn, H. Thienpont, The potential of UV-VIS-NIR absorption spectroscopy in glass studies, in: Integrated approaches to the study of historical glass - IAS12, SPIE, 2012, pp. 11.

[26] N.D. Baydoğan, Evaluation of optical properties of the amorphous carbon film on fused silica, Materials Science and Engineering: B, 107 (2004) 70-77. 